\title{
MORFOLOGIA DAS CERDAS EM GANCHO NO EXOESQUELETO DO CARANGUEJO DECORADOR MACROCOELOMA TRISPINOSUM (LATREILLE, 1825) (CRUSTACEA: DECAPODA: BRACHYURA)
}

\author{
Lianos, L. ${ }^{1,2,}$; Zara, F.J. ; Mollemberg, M. ${ }^{1,2} \&$ Santana, W. ${ }^{1,2}$ \\ ${ }^{1}$ Universidade Estadual Paulista Júlio de Mesquita Filho (UNESP), Campus Botucatu, Laboratório de Sistemática \\ Zoológica. \\ ${ }^{2}$ Universidade do Sagrado Coração (USC), Campus Bauru, Laboratório de Sistemática Zoológica. \\ ${ }^{3}$ Universidade Estadual Paulista (UNESP), Campus Jaboticabal, Laboratório de Morfologia de Invertebrados. \\ *Autor correspondente: lahlianos@hotmail.com
}

Diversos organismos dos mais variados filos aderem materiais exógenos sobre suas estruturas corporais, sendo tal comportamento denominado decoração. As espécies de caranguejos Majoidea (Samouelle, 1819) estão intimamente relacionadas a esponjas, anêmonas e corais, já que utilizam este ambiente como refúgio de predadores, fonte alimentar, reprodução e simbiose. Majoidea representa um dos grupos de caranguejos decoradores mais estudados, onde as espécies desta superfamília utilizam seus quelípodos para agarrar, triturar e direcionar diversos elementos sobre sua carapaça. Estes materiais são aderidos ao exoesqueleto por fricção mecânica, e as cerdas em formato de gancho funcionam como velcro. Até o momento, todos os registros analisaram superficialmente estas cerdas, e por este motivo as informações fisiológicas não são bem esclarecidas. Desta forma, por meio de análises histológicas, histoquímicas e microscopia eletrônica de varredura (MEV), o presente estudo descreve as cerdas em gancho encontradas no exoesqueleto de Macrocoeloma trispinosum (Latreille, 1825). Espécimes de M. trispinosum provenientes de Boca del Rio e em Bajo de Piedras, Venezuela foram mensurados e dissecados em estereomicroscópio para retirada de fragmentos da carapaça. Em seguida, as amostras foram submetidas aos protocolos de histologia, histoquímica e MEV. Os resultados demonstraram a presença de cerdas em gancho com padrão de inserção supracuticular na carapaça desses animais. Além disso, estas cerdas possuem estrutura tubular bastante delgada com a superfície retorcida e extremidade distal curvada. Também foi observada uma grande quantidade de cristais de sais aderidos entre as inúmeras fileiras de cerdas. Todas essas características morfológicas observadas fazem parte do aparato de camuflagem utilizado por M. trispinosum, onde a estratégia de decoração é fundamental no sucesso e sobrevivência desta espécie.

Palavras-chave: camuflagem, decoração, Majoidea.

Financiamento: FAPESP \#2013/01201-0, FAPESP Biota \#2010/50188-8, CAPES CIMAR II \# 1989/2014, CNPQ \# 141394/2018-8. 